Provided for non-commercial research and education use. Not for reproduction, distribution or commercial use.

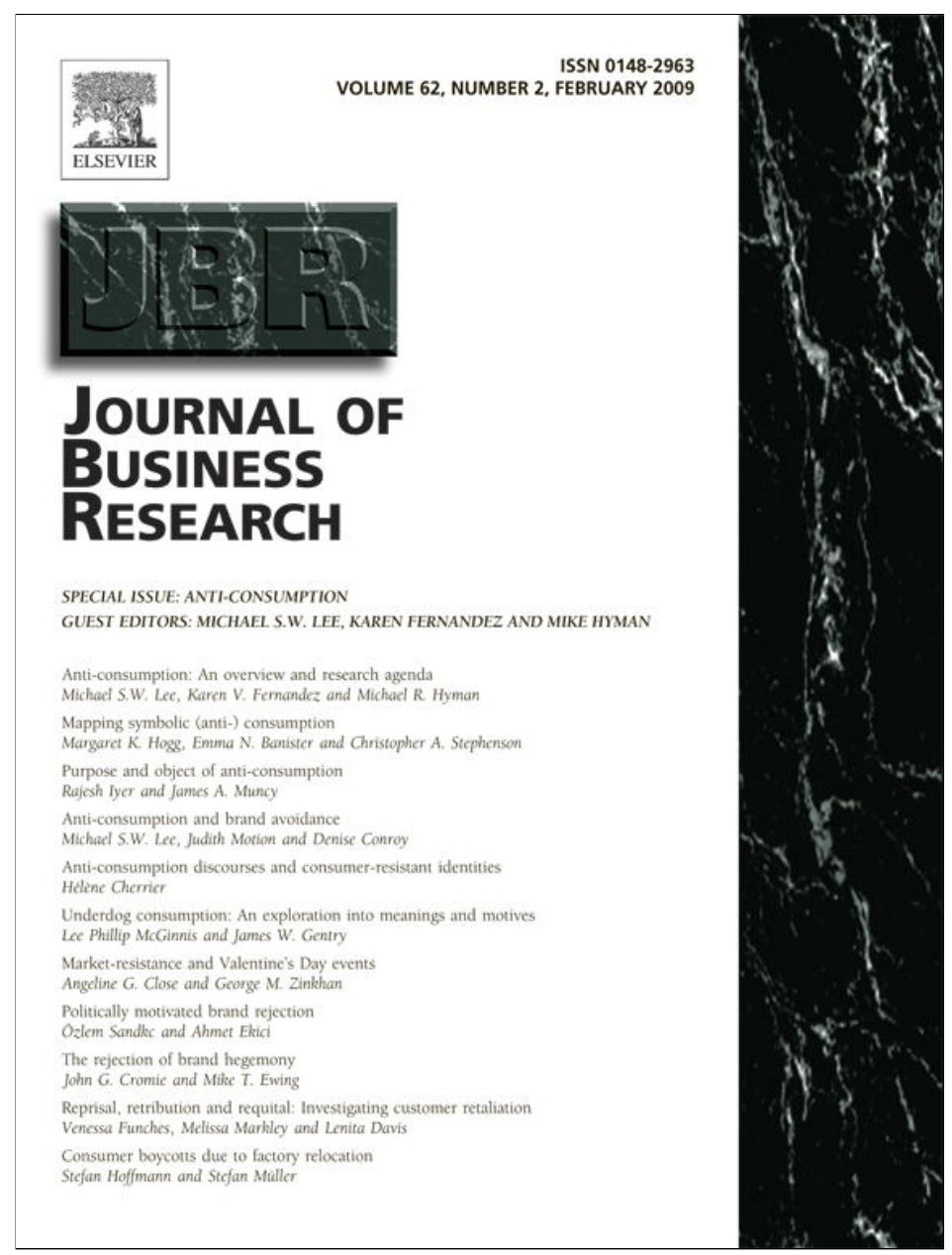

This article appeared in a journal published by Elsevier. The attached copy is furnished to the author for internal non-commercial research and education use, including for instruction at the authors institution and sharing with colleagues.

Other uses, including reproduction and distribution, or selling or licensing copies, or posting to personal, institutional or third party websites are prohibited.

In most cases authors are permitted to post their version of the article (e.g. in Word or Tex form) to their personal website or institutional repository. Authors requiring further information regarding Elsevier's archiving and manuscript policies are encouraged to visit:

http://www.elsevier.com/copyright 


\title{
Editorial
}

\section{Anti-consumption: An overview and research agenda}

\begin{abstract}
This introduction to the Journal of Business Research special issue on anti-consumption briefly defines and highlights the importance of anticonsumption research, provides an overview of the latest studies in the area, and suggests an agenda for future research on anti-consumption. (C) 2008 Elsevier Inc. All rights reserved.
\end{abstract}

Keywords: Anti-consumption; Definition; Overview; Research agenda

\section{What is anti-consumption research?}

Anti-consumption literally means against consumption, yet the word is not synonymous with alternative, conscientious, or green consumption; neither does anti-consumption merely comprise the study of ethics, sustainability, or public policy. Although some consumers may affirm their anti-consumption attitudes through non-standard consumption and/or lifestyle choices - for example, buying environmentally friendly brands when possible - anti-consumption research focuses on reasons against consumption rather than pro-social movements. Generally, consumer research focuses on approach aspects of consumer behaviours and attitudes; for instance, why people choose a product or brand. In contrast, anti-consumption research focuses on consumers' reasons for avoiding a product or brand. A complete understanding of consumers' decisions requires careful study from both orientations. Alternative, conscientious, green, and sustainable consumption simply describe various forms of pro-social consumption; anti-consumption, on the other hand, focuses on phenomena that researchers traditionally have ignored.

Anti-consumption need not be contrary to business success or enhanced quality of life, nor need it interfere with societal and business progress. Consumer research can and should entail more than ways to increase consumption. Likewise, anti-consumption research can and should entail more than ways to reduce consumption. From a marketing perspective, enhanced quality of life depends on improving both the quantity and quality of consumption; thus, anti-consumption is not an inherent economic threat. Business practitioners and academicians should view acts of anti-consumption as opportunities to learn about ourselves, our products, our practices, and our society.

By providing a disparate perspective for studying consumers, anti-consumption forces people to change their perspectives and focus, thus enhances learning for scholars, practitioners, and people. Physicians who understood health but not illness could not treat their patients successfully; analogously, business scholars who only study successful companies may never understand what causes unsuccessful companies. Therefore, studying consumption phenomenon without studying its antithesis limits our understanding of consumers.

\section{The special issue}

Ultimately, it is the progress at the margins of humanity that drives civilisation forward. Likewise, knowledge harvested from both ends of the consumption continuum will increase understanding of consumers, consumer culture, and society. In line with this philosophy, The International Centre for Anticonsumption Research (ICAR) was established in 2005 to provide a network by which academics and practitioners could share their interest in anti-consumption. ICAR consists of more than 50 affiliates, with diverse yet complementary backgrounds, spread across eleven countries. In June 2006, ICAR held its first symposium at The University of Auckland Business School in New Zealand. The symposium successfully brought together researchers from diverse research paradigms, academic disciplines and geographical regions, creating synergy and establishing a scholarly network that continues to grow. (Please visit www. icar.auckland.ac.nz to learn more about ICAR, its affiliates, and forthcoming events, such as the 2008 ICAR symposium to be hosted by The University of Sydney.)

Prior to the first symposium, Arch Woodside, Editor-in-Chief of Journal of Business Research, contacted Michael Lee, the symposium organiser, about a special issue based on the event. An agreement was reached quickly and an official call-for-papers inviting both symposium and non-symposium related manuscripts - was issued. The large number (55) of papers submitted to special issue highlights both the extremely competitive nature of this special issue and growing interest in anti-consumption research. All articles in this special issue were subjected to two 
double-blind review rounds, a third and final review by the guest editors, and final approval by Arch Woodside. This rigorous process netted the outstanding set of articles herein.

This editorial has introduced the topic of anti-consumption, the next article develops it conceptually, and the third article suggests a way of measuring anti-consumption. In "Mapping Symbolic (Anti-) Consumption," Hogg, Banister, and Stephenson conceptualize an expanded framework of symbolic consumption that offers a road map for further theory-building and empirical work in symbolic consumption. In "Purpose and Object of AntiConsumption," Iyer and Muncy develop a scale to measure the anti-consumption attitudes on two understudied groups: simplifiers and global impact consumers. In doing so, they explore how anti-consumption relates to other key constructs, such as self consciousness, self-actualization, and assertiveness.

The second set of three articles discusses how consumers' practice of anti-consumption via brand avoidance helps them express identity and satisfy motives. In "Anti-Consumption and Brand Avoidance," Lee, Motion, and Conroy present three types of brand avoidance: experiential, identity, and moral brand avoidance. They highlight potential strategies for managers to handle brand avoidance. In "Anti-Consumption Discourses and Consumer-Resistant Identities," Cherrier's analysis of two dominant anti-consumption discourses - the voluntary simplicity discourse and the culture jammer discourse) - shows the importance of anticonsumption practices in the construction of hero and project consumer identities. In "Underdog Consumption: An Exploration into Meanings and Motives," McGinnis and Gentry show the approach and avoidance aspects of consumption and anti-consumption. They conclude that although some motives for underdog support can be interpreted as anti-consumptive in nature, most people support and identify with underdogs as a way to keep the little guy competing rather than as a way to keep the top dog down.

The third set of three articles describes how consumers reject commercialized celebrations, politized brands, and commercialized software. In "Market-resistance and Valentine's Day Events," Close and Zinkhan use multiple data sources to study resistance to consumption activities normally associated with Valentine's Day. They find this resistance permits some consumers to construct consumption constellations that are more unique and personalized than those associated with commercialized/normative Valentine's Day. In "Politically Motivated Brand Rejection," Sandikci and Ekici introduce and discuss an emergent form of anti-consumption behaviour: politically motivated brand rejection. They analyze how globalization, nationalism, and fundamentalism trigger rejection of certain brands and provide a rare glimpse into consumption in a Middle-Eastern context. In "The Rejection of Brand Hegemony," Cromie and Ewing explore the rejection of brand hegemony through a phenomenological study of the open-sourcesoftware community. They indicate that positive motivations towards the use of open-source software, negative motivations against the use of the market dominant brand (Microsoft), and certain environmental conditions all influence the development of hegemonic brand resistance.

The fourth set of three articles uncovers a range of retaliatory behaviours, investigates the retaliatory behaviour of boycotting in depth, and evaluates strategic responses to those types of be- haviour. In "Reprisal, Retribution and Requital: Investigating Customer Retaliation," Funches, Markley and Davis identify the specific roles that retaliating customers adopt, customer emotions and store issues that induce retaliatory behaviours, and categories of retaliatory behaviours. One of these retaliatory behaviours, boycotting, is the focus of the other two articles in this set. In "Consumer Boycotts Due to Factory Relocation," Hoffmann and Mueller reveal that the effects of boycotting are stronger among customers than non-customers; consequently, the authors argue that customer identification with a company may not always benefit that company. They also provide potential managerial insights for managing the controversial relocation of a factory. In "An Evaluation of Strategic Responses to Consumer Boycotts," Yuksel and Mryteza examine the relative effectiveness of various marketing strategies, and in particular the public relations strategies used to combat the likelihood of boycotts as a politically motivated form of anti-consumption.

The last set of three articles suggests that social marketing approaches can contribute meaningfully to anti-consumption. In "Social Marketing: A Pathway to Consumption Reduction?," Peattie and Peattie show, through a health-orientated social marketing campaign, that a social marketing approach can address ingrained forms of consumer behaviour and de-market harmful products. In "Demarketing Tobacco through Governmental Policies - The 4Ps Revisited," Shiu, Hassan, and Walsh summarize their longitudinal study of people's intentions to quit smoking. They conclude that successful anti-smoking campaigns should consider the entire marketing mix. Finally, in "Managing Anticonsumption in an Excessive Drinking Culture," Piacentini and Banister contribute to social marketing and anti-consumption research by exploring a counter cultural phenomenon: English University students who are against excessive consumption of alcohol. They discuss the ways in which study participants resolved tensions between their internal desire to imbibe in moderation and the prevailing norm of excessive alcohol consumption.

\section{Agenda for future research on anti-consumption}

The guest editors hope this special issue not only excites scholars currently enthused about anti-consumption research, but that it also raises questions that will broaden the appeal of anticonsumption research. Fortuitously, many of the articles featured in this special issue should provide knowledge while stimulating curiosity.

This nationally and culturally diverse group of authors relied on disparate paradigmatic perspectives, methodologies, and data sets. Despite this melange, several articles independently arrive at conclusions that support the conceptualizations of anti-consumption in other articles. This convergence supports our premise that a grand theory of anti-consumption is feasible. One such recurrent theme is the difference between anti-consumption driven by personal motivations and anti-consumption driven by societal and ideological factors. Some scholars may argue that a person's ideological orientation is integral to his or her sense of self, and therefore the two are inseparable. However, the saliency and clarity with which these two themes (I versus We) were consistently distinguished from one another across several studies (Cromie and Ewing; 
Cherrier; Iyer and Muncy; Lee, Motion, and Conroy; Piacentini and Banister; and Sandikci and Ekici) suggests that this perspective may help to organize future studies of anti-consumption phenomena. Specifically, the guest editors suggest that scholars investigate whether anti-consumption behaviour is proactive (internally driven) or reactive (externally driven). Future researchers may also choose to explore the differences between selectively practiced anti-consumption (e.g., politically motivated brand avoidance) and generally practiced anti-consumption (e.g., a lifestyle choice such as voluntary simplification).

Additionally, the final sets of articles on social marketing allude to a research domain that deserves special attention. Although anti-consumption and social marketing are not identical concepts, many social marketing campaigns are based on encouraging anti-consumption of undesirable products or activities. Therefore, those articles suggest an opportunity for anticonsumption researchers to contribute meaningfully to consumers and society. Credible scientific reports warn of a downturn in petroleum production and an upturn in global warming. Consequently, the guest editors call for anti-consumption research that will uncover effective ways to persuade consumers to reduce their current energy consumption, even if they personally may not enjoy the benefits of their sacrifices.

Finally, the guest editors' call for longitudinal research that could uncover the processes that underlie the outcomes described in this special issue. Understanding the cognitive, emotional and behavioural processes that result in anticonsumption outcomes will enable marketers to devise strategies to pre-emptively avoid, pro-actively influence, and/or reactively mitigate those outcomes.

\section{List of Reviewers}

Anderson, Laurel, Arizona State University

Aron, David, Brennan School of Business, Dominican University

Aslanbay, Yonca, Istanbul Bilgi University, Turkey

Ballantine, Paul W., University of Canterbury, New Zealand

Becker, Boris W., Oregon State University

Brookes, Richard, The University of Auckland Business School, New Zealand

Buchanan-Oliver, Margo, The University of Auckland Business School, New Zealand

Carlson, Les, Clemson University

Dalli, Daniele, University of Pisa, Italy

Gardner, Meryl P., University of Delaware

Hampton, Gerald, New Mexico State University

Handelman, Jay, Queens University, Canada

Hardie, Bruce, London Business School, United Kingdom

Heiser, Robert S., University of Southern Maine

Heslop, Louise A., Carleton University

Jaeger, Sara, HortResearch, Auckland, New Zealand

James, William L., Zarb School of Business, Hofstra University Joseph, Richard, The University of Auckland Business School, New Zealand

Kerr, Anthony H., Southeastern Louisiana University

Kilbourne, William E., Clemson University
Kleine, Robert E. III, Ohio Northern University

Kleine, Susan Schultz, Bowling Green State University

Kopf, Dennis, New Mexico State University

Kozinets, Robert V., Schulich School of Business, York University

Kuang, Xiao Dong, University of Wisconsin-Madison

Lastovicka, John L., Arizona State University

Lee, Dongdae, Dong-A University, Korea

Martin, Diane M., University of Portland

Martinec, Radan, Ohio Northern University

Mcdonald, Bob, Texas Tech University

Minahan, Stella, Deakin University, Australia

Mish, Jenny, University of Utah

Parsons, Andrew, Auckland University of Technology

Pokrywczynski, James, Marquette University

Polonsky, Michael, Victoria University, Australia

Richards, Jef I., The University of Texas at Austin

Roux, Dominique, University Paris 12

Rumbo, Joseph D., James Madison University

Sierra, Jeremy J., Northern Arizona State University

Sobh, Rana, Qatar University

Speck, Sandra K., Idaho State University

Starr, Richard G. III, The University of Auckland Business

School, New Zealand

Taylor, James S., The College of New Jersey

Veer, Ekant, Bath University

Viswanathan, Madhu, University of Illinois Urbana-Champaign

Wise, Jorge A., Tec de Monterrey, Mexico

Witkowski, Terry H., California State University-Long Beach

Zavestoski, Steve, University of San Francisco

\section{Acknowledgements}

We applaud the many dedicated scholars whose support was vital to this special issue of Journal of Business Research. We humbly recognize all manuscript submitters for considering this special issue as an outlet for their work. For scholars whose articles appear here, we appreciate your dedication to and patience with a demanding revision process. We commend our many colleagues who volunteered their time and energy to help us provide authors with useful feedback. Finally, we thank Arch Woodside for his helpful direction, encouragement, and approval of this special issue.

Michael S.W. Lee*

Karen V. Fernandez

The University of Auckland Business School, New Zealand

* Corresponding author. Department of Marketing, The University of Auckland Business School, Private Bag 92019, and Auckland 1142, New Zealand. Tel.: +64 93737 599x85953.

E-mail address: msw.lee@auckland.ac.nz (M.S.W. Lee).

Michael R. Hyman New Mexico State University, United States

1 June 2007 